\title{
NCEP-ATP III and IDF criteria for metabolic syndrome predict type 2 diabetes mellitus
}

\author{
Eva Sulistiowati* and Marice Sihombing*
}

\begin{tabular}{l}
\hline \\
\hline *Center for Applied Health \\
Technology and Clinical \\
Epidemiology \\
Correspondence : \\
dr. Eva Sulistiowati \\
Center for Applied Health Technology \\
and Clinical Epidemiology \\
J1. Percetakan Negara 29 Jakarta \\
Pusat 10560 \\
Phone: +6221 4259860, \\
Fax: +6221 4244375 \\
Email: dr.eva_s@yahoo.com
\end{tabular}

Univ Med 2016;35:46-55

DOI: 10.18051/UnivMed.2016.v35.46-55 pISSN: 1907-3062 / eISSN: 2407-2230

This open access article is distributed under a Creative Commons Attribution-Non Commercial-Share Alike 4.0 International License

\section{BACKGROUND}

Subjects with metabolic syndrome (MetS) have a greater risk for acquiring type 2 diabetes mellitus (type $2 \mathrm{DM}$ ). The MetS criteria usually used are those of the National Cholesterol Education Program Expert Panel (NCEP) and Adult Treatment Panel III (ATP III) and of the International Diabetes Federation (IDF). This study aimed to evaluate the modified NCEP-ATP III and IDF criteria as predictor of type 2 DM among subjects with MetS.

\section{METHODS}

A cohort study was conducted among 4240 subjects with MetS. MetS was determined according to the modified NCEP-ATP III and IDF criteria. The study followed up 3324 non-diabetic subjects of the cohort study of non-communicable disease (NCD) risk factors (NCD study) during a 2year period. Type $2 \mathrm{DM}$ was determined from the diagnosis by health personnel or from fasting blood glucose of $\geq 126 \mathrm{mg} / \mathrm{dL}$ or blood glucose of $\geq 200 \mathrm{mg} / \mathrm{dL}, 2$ hours after $75 \mathrm{~g}$ glucose loading.

\section{RESULTS}

The MetS prevalence based on modified NCEP ATP III and IDF criteria in non-DM subjects was $17.1 \%$ and $15.6 \%$, respectively. The risk for DM in subjects with MetS using modified NCEP ATP III and IDF criteria was 4.7 (CI 95\%: 3.4-6.5) and 4.1 (CI 95\%: 3.0-5.7), respectively.

\section{CONCLUSIONS}

Both MetS criteria can be used as predictors of the occurrence of DM type 2, but the modified NCEP-ATP III is more properly applied than the IDF criteria in subjects with MetS. Screening programs and routine monitoring of MetS components are required for early detection of type 2 DM.

Keywords: Metabolic syndrome, National Cholesterol Education Program Expert Panel and Adult Treatment Panel III, type 2 diabetes mellitus 


\section{INTRODUCTION}

The metabolic syndrome (MetS) is one of a cluster of metabolic risk factors that include central obesity, hyperglycemia/glucose intolerance, hypertension, low HDL cholesterol levels, and high triglyceride levels. ${ }^{(1-3)}$ The factors that affect the occurrence of MetS are among others gender, age, race/ethnicity, genetic factors, obesity, food intake, physical activity, alcohol consumption and smoking habit. ${ }^{(4)}$ The criteria for the definition of MetS are variable, since there are different definitions of MetS, depending on the respective health organizations, such as the World Health Organization, the National Cholesterol Education Program Expert Panel (NCEP) and Adult Treatment Panel III (ATP III), the European Group for Study of Insulin Resistance (EGIR) and the International Diabetes Federation (IDF). ${ }^{(1-3)}$

The WHO criteria emphasize the occurrence of insulin resistance with impaired fasting glucose (IFG), where fasting glucose is $100-125 \mathrm{mg} / \mathrm{dL}$, or impaired glucose tolerance (IGT) where blood glucose level 2 hours after loading with $75 \mathrm{~g}$ glucose is $140-199 \mathrm{mg} / \mathrm{dL}$, or on measuring the homeostatic model assessment of insulin resistance (HOMA-IR) value, in which fasting insulin and fasting glucose are compared. ${ }^{(1)}$ The NCEP-ATP III criteria for the year 2004 are a combination of hyperglycemia, central obesity, atherogenic dyslipidemia and hypertension. These criteria are more frequently used because they are more simple and reliable compared with other criteria, ${ }^{(5)}$ whereas the IDF focus on the presence of central obesity, even in the absence of insulin resistance, together with 2 or more components. The cut-off point for central obesity depends on the population, ethnic group, and gender. ${ }^{(1)}$

The MetS prevalence is currently steadily increasing in many countries concomitant with the high rates of general and central obesity in the community. ${ }^{(6)}$ In individuals with MetS, the morbidity and mortality risks increase as a result of cardiovascular disease and diabetes mellitus (DM). Several studies have shown that subjects with MetS have a three-fold greater risk for experiencing myocardial infarction or stroke and a five-fold greater risk for suffering from type 2 DM. ${ }^{(7-13)}$ The British Regional Heart Study (BRHS) and the Prospective Study of Pravastatin in Elderly at Risk (PROSPER) in the UK have also shown that MetS carries a 7.5- and 4.4 times greater risk for the occurrence of DM. ${ }^{(10)} \mathrm{A}$ cohort study conducted by Dekker et al. ${ }^{(11)}$ for 10 years on non-DM subjects showed that MetS has a 2fold increased morbidity and mortality risk as a result of cardiovascular disease. Individuals having $\geq 3$ MetS components and central obesity have a 10 -fold greater risk for DM. ${ }^{(12)}$ These research results found different risks for DM, depending on the MetS criteria used. ${ }^{(13)}$

The MetS prevalence based on the NCEPATP III criteria in Jakarta is $28.4 \%,{ }^{(5)}$ whereas that based on the IDF criteria among subjects of the cohort study of non-communicable disease (NCD) risk factors (3945 subjects) is $14.1 \% .^{(14)}$ The risk of DM in non-DM subjects with MetS in the cohort study of NCD risk factors have not been further analyzed. Therefore, this study aimed to find the prevalence of MetS based on the NCEPATP III and IDF criteria and the risk of type 2 DM in respondents with MetS among non-DM subjects.

\section{METHODS}

\section{Study design}

An observational study using a cohort approach was conducted from 2011 to 2014 in five kelurahan [villages], i.e. Kebon Kalapa, Ciwaringin, Panaragan, Babakan and Babakan Pasar), Central Bogor District, Bogor City.

\section{Study subjects}

The study subjects were 25-65 year-old respondents of the cohort study of NCD risk factors (baseline data for the years 2011 and 2012), who were permanent residents of five kelurahan in Central Bogor District, Bogor City, and whose data were complete. These baseline data had been collected with the WHO STEPS 
method, comprising interviews, physical examination, and laboratory investigations. ${ }^{(14)}$ The respondents with these baseline data were 5280 in number, but 468 of these individuals had type $2 \mathrm{DM}$ (161 persons had been diagnosed as having DM by health personnel, 307 persons had undiagnosed diabetes mellitus based on their blood glucose levels), and 472 persons had not undergone laboratory tests or had incomplete tests. The respondents with type $2 \mathrm{DM}$ who had not undergone laboratory tests were removed from the baseline data and the final number of respondents was 4340 persons ( 1518 males and 2822 females). The respondents with MetS on the baseline data who had a follow-up in the second year, were to be subjected to an analysis of their risk factors for type $2 \mathrm{DM}$. The evaluation in the second year could only be performed on $81 \%$ respondents with MetS (601 persons with MetS according to the modified NCEP-ATP III criteria and 549 persons with MetS according to IDF criteria).

\section{Laboratory investigations}

Venous blood samples to a volume of $8 \mathrm{ml}$ were collected by experienced laboratory technicians from the respondents after a 10-12 hour fast. The collection of the blood samples was conducted in the Center for Applied Health Technology and Clinical Epidemiology in Bogor. The blood samples were centrifuged at $5000 \mathrm{rpm}$ for 3 minutes and subsequently the plasma was separated from the serum. From the serum samples, the blood glucose, total cholesterol, low density lipoprotein (LDL), high density lipoprotein (HDL) and triglyceride concentrations were determined at Prodia Laboratories, Bogor. On the other hand, the plasma samples were sent to the Biomedical and Health Technology Center for determination of other laboratory indicators.

Blood glucose concentration was determined with the glucose hexokinase II (GLUH) method, total cholesterol with a standard enzymatic method, LDL and HDL cholesterol was determined by a standard homogeneous method, while for triglyceride measurement the glycerol-3-phosphate oxidase
(GPO) method was used. These investigations were performed with the Hitachi model 747 automatic analyzer. The subjects were said to be at risk if they had a total cholesterol concentration of $\geq 200 \mathrm{mg} / \mathrm{dL}$, triglyceride concentration of $\geq 150 \mathrm{mg} / \mathrm{dL}$, LDL cholesterol $\geq 100 \mathrm{mg} / \mathrm{dL}$, and HDL cholesterol $<40 \mathrm{mg} / \mathrm{dL}$ for males and $<50 \mathrm{mg} / \mathrm{dL}$ for females. A second blood sample of $1 \mathrm{ml}$ was collected 2 hours post loading with $75 \mathrm{~g}$ glucose. These blood samples were handled similarly as in the blood glucose determination. ${ }^{(18)}$

\section{NCEP-ATP III and IDF criteria for the metabolic syndrome}

The metabolic syndrome was diagnosed according to the criteria of the National Cholesterol Education Program Expert Panel (NCEP) and Adult Treatment Panel III (ATP III), that were modified in 2004 and adapted for Asians, and of the International Diabetes Federation (IDF) for 2005. According to the modified NCEP-ATP III criteria for Asians, the definition of MetS comprises the clinical condition meeting at least 3 or more than 5 risk factors, i.e. central obesity (waist circumference $\geq 90 \mathrm{~cm}$ for males and $\geq 80 \mathrm{~cm}$ for females), low HDL cholesterol (males $<40 \mathrm{mg} / \mathrm{dL}$ and females $<50 \mathrm{mg} / \mathrm{dL}$, or under treatment), high serum triglycerides $(\geq 150 \mathrm{mg} / \mathrm{dL}$, or under treatment), increased blood pressure $(\geq 130 / 85 \mathrm{mmHg}$ or under treatment), and fasting blood glucose $\left(\geq 100 \mathrm{mg} / \mathrm{dL}\right.$ or under treatment). ${ }^{(4)}$ In contrast, according to the IDF, the metabolic syndrome must have central obesity (modification for Asians: waist circumference $>90 \mathrm{~cm}$ in males and $>80 \mathrm{~cm}$ in females), with 2 additional criteria from among the following: triglyceride level $\geq 150 \mathrm{mg} / \mathrm{dL}$, HDL cholesterol $(<40 \mathrm{mg} / \mathrm{dL}$ in males and $<50 \mathrm{mg} / \mathrm{dL}$ in females), blood pressure $\geq 130 / 85 \mathrm{mmHg}$ and fasting blood glucose $\geq 100$ $\mathrm{mg} / \mathrm{dL} \cdot{ }^{(16)}$

\section{Criteria for type $2 \mathrm{DM}$}

Type 2 diabetes mellitus was determined based on the results of interviews, in which the 
subjects knew that they suffered from DM or had been diagnosed by health personnel and/or by laboratory determination of fasting blood glucose of $\geq 126 \mathrm{mg} / \mathrm{dL}$ and/or blood glucose level of $\geq 200$ $\mathrm{mg} / \mathrm{dL}$, at 2 hours after loading with $75 \mathrm{~g}$ glucose (ADA criteria, 2003). ${ }^{(17)}$

\section{Measurements}

The waist circumference was measured by means of measuring tape. The respondents were asked to stand upright with the feet together, and avoid wearing heavy clothing. The waist circumference was measured by extending the measuring tape around the abdomen from the midpoint between the lower ribs and the iliac crest. For a prominent abdomen, the most protruding part was taken for measurement. Obesity was determined based on body mass index (BMI) calculated with the formula: weight $(\mathrm{kg}) / \mathrm{height}$ $(\mathrm{m})^{2}$. The subject was said to be obese if the BMI was $\geq 25.0$ (according to recommendations of the Indonesian Ministry of Health). ${ }^{(18)}$ Hypertension was determined based on interview results, in which the subjects knew that they had hypertension or had been diagnosed by health personnel, while their blood pressure measurements indicated hypertension according to JNC VII, and the subjects had a history of consuming anti-hypertensive drugs. Measurement of blood pressure was performed in the sitting position on the right arm using a digital sphygmomanometer. The measurement was performed twice with an interval of \pm 3 minutes, and if there was a difference of $\geq 10 \mathrm{mmHg}$ between the two blood pressure measurements, either systolic or diastolic, then a third measurement was performed after a 10-minute resting period. ${ }^{(18)}$ Total cholesterol, triglyceride, low density lipoprotein (LDL) and high density lipoprotein (HDL) cholesterol concentrations were determined after a fast of 10-12 hours. The subjects were said to be at risk if the total cholesterol was $\geq 200 \mathrm{mg} / \mathrm{dL}$, the triglyceride concentration was $\geq 150 \mathrm{mg} / \mathrm{dL}$, LDL cholesterol $\geq 100 \mathrm{mg} / \mathrm{dL}$, and HDL cholesterol $<40 \mathrm{mg} / \mathrm{dL}$ for males and $<50 \mathrm{mg} / \mathrm{dL}$ for females. ${ }^{(18)}$

\section{Ethical clearance}

The baseline data collection and follow-up program of the cohort study of NCD risk factors obtained ethical clearance from the Commission of Health Research Ethics, Health Research and Development Agency, Ministry of Health, Republic of Indonesia.

\section{Data analysis}

Multivariate analysis was performed and agreement between NCEP ATP III and IDF criteria was determined using the kappa $(\kappa)$ statistic. The interpretation of the kappa agreement was as follows: slight if $\kappa=0-0.20$; fair if $\kappa=0.21-0.40$; moderate if $\kappa=0.41-0.60$; substantial if $\kappa=0.61$ 0.80 ; almost perfect if $\kappa>0.80 .^{(12,19)}$

\section{RESULTS}

Non-DM respondents with MetS in the baseline data based on the NCEP-ATP III criteria were 743 in number (17.1\%), while those based on IDF criteria were 676 in number (15.6\%). Females had a higher proportion of MetS than males, based on NCEP-ATP III ( $21.1 \%$ and $9.7 \%$ ) as well as on IDF criteria (11.2\% dan 5.9\%). The metabolic syndrome occurred at the mean age of 47 years. Mean waist circumference, BMI, LDL cholesterol, total cholesterol, and systolic and diastolic pressures in respondents with MetS were greater as compared with residents without MetS, either based on NCEP-ATP III or IDF criteria, whereas HDL cholesterol was lower (Table 1).

All respondents with MetS based on IDF criteria were also found to have MetS based on NCEP-ATP III criteria, while $9 \%$ of respondents who were said to have MetS according to NCEPATP III criteria were considered to have no MetS according to IDF criteria. Kappa agreement between NCEP-ATP III and IDF criteria was 0.94 ( $p<0.001$; CI 95\%: 0.93-0.96) or very good (almost perfect).

Figure 1 shows that the percentage of MetS based on NCEP-ATP III as well as on IDF criteria increased concomitantly with increasing age, as was also the case with the number of MetS 
Table 1. Distribution of characteristics of non-DM subjects at base-line ( $n=4340)$

\begin{tabular}{lcccc}
\hline & \multicolumn{4}{c}{ Metabolic Synd rome criteria } \\
\cline { 2 - 5 } \multicolumn{1}{c}{ Variab le } & \multicolumn{2}{c}{ Modified NCE P-ATP III } & IDF \\
\cline { 2 - 5 } & $\begin{array}{c}\text { MetS } \\
(\mathbf{n = 7 4 3 )}\end{array}$ & $\begin{array}{c}\text { No MetS } \\
(\mathbf{n = 3 5 9 7 )}\end{array}$ & $\begin{array}{c}\text { MetS } \\
(\mathbf{n = 6 7 6 )}\end{array}$ & $\begin{array}{c}\text { No MetS } \\
\text { (n=3,664) }\end{array}$ \\
\hline Male (\%) & 9.7 & 90.3 & 5.9 & 94.1 \\
Fem ale (\%) & 21.1 & 78.9 & 11.2 & 88.8 \\
Age & $47.0 \pm 9.2$ & $42.8 \pm 10.3$ & $46.7 \pm 9.2$ & $42.9 \pm 10.3$ \\
Waist circumference & $90.1 \pm 8.8$ & $77.8 \pm 19.1$ & $91.1 \pm 8.2$ & $77.8 \pm 19.0$ \\
BMI & $28.7 \pm 4.0$ & $23.7 \pm 4.2$ & $29.1 \pm 3.9$ & $23.7 \pm 4.1$ \\
Trigjycerides & $162.1 \pm 90.0$ & $99.3 \pm 50.5$ & $159.9 \pm 84.8$ & $100.8 \pm 54.2$ \\
HDL cholesterd & $45.6 \pm 10.4$ & $51.5 \pm 10.9$ & $45.7 \pm 10.3$ & $51.4 \pm 10.9$ \\
LDL cholesterol & $144.6 \pm 32.0$ & $125.0 \pm 31.3$ & $145.8 \pm 31.9$ & $125.2 \pm 31.3$ \\
Cholesterol tot al & $224.1 \pm 34.8$ & $196.9 \pm 36.6$ & $224.9 \pm 34.8$ & $197.3 \pm 36.6$ \\
Fasting blood glucose & $87.6 \pm 11.0$ & $83.7 \pm 8.5$ & $86.8 \pm 10.5$ & $83.9 \pm 8.8$ \\
2-h PP blood glucose & $133.1 \pm 2.0$ & $114.4 \pm 27.6$ & $132.4 \pm 28.7$ & $114.9 \pm 27.9$ \\
Systolic BP & $145.6 \pm 28.4$ & $124.5 \pm 21.6$ & $144.4 \pm 28.2$ & $125.1 \pm 22.1$ \\
Diastolic BP & $89.6 \pm 13.6$ & $78.1 \pm 12.3$ & $89.3 \pm 13.3$ & $78.4 \pm 12.5$ \\
\hline
\end{tabular}

components. Based on NCEP-ATP III criteria, the respondents in the age group of 25-35 years had only 3-4 MetS components, but starting with the age of $\geq 36$ years the respondents had 5 MetS components. Similarly with the IDF criteria, the age group of 25-35 years had central obesity with 2-3 MetS components only.

Respondents with MetS who participated in the follow-up accounted for $81 \%$. The observational results showed that there were 78 cases with type 2 DM (13.0\%) among the respondents with MetS according to NCEP-ATP III criteria, while among the respondents with MetS according to IDF criteria, there were 69 cases with type $2 \mathrm{DM}$ (12.6\%). Respondents who experienced type $2 \mathrm{DM}$ had significantly higher mean values for age, triglyceride, HDL, LDL, total cholesterol, fasting blood glucose and 2-hour pp blood glucose, compared with subjects without DM $(p<0.05)$. On the other hand, waist circumference and BMI did not show significant differences. These results can be seen in Table 2 .

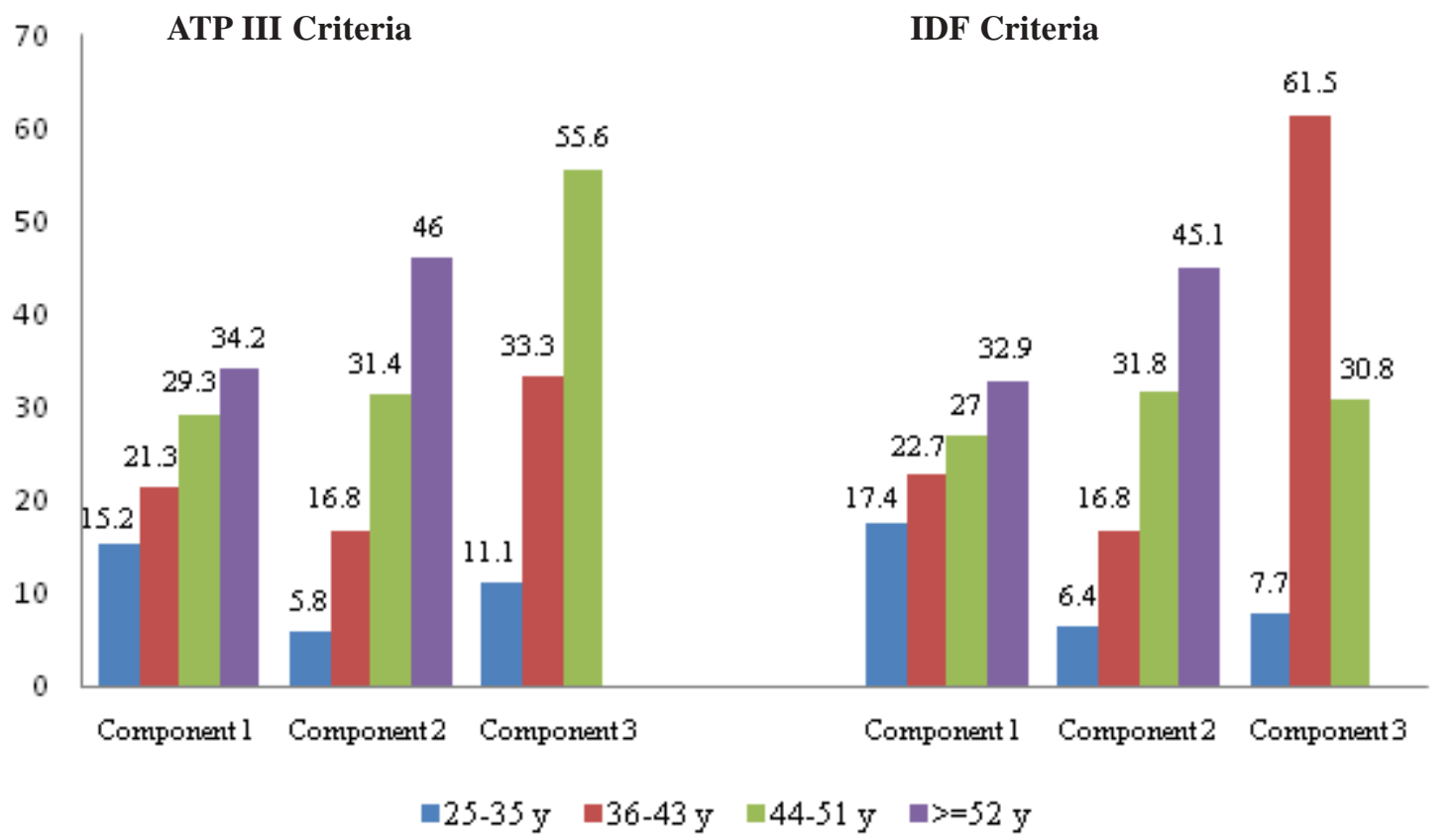

Figure 1. Percentages of metabolic syndrome components by age group 
Table 2. Distribution of characteristics of subjects with the metabolic syndrome who had type $2 \mathrm{DM}$ after 2 years

\begin{tabular}{|c|c|c|c|c|c|c|}
\hline \multirow[b]{2}{*}{ Variable } & \multicolumn{2}{|c|}{ MetS ATP III $(n=601)$} & \multirow[b]{2}{*}{$\mathbf{p}$} & \multicolumn{2}{|c|}{ MetS DF $(n=549)$} & \multirow[b]{2}{*}{$\mathbf{p}$} \\
\hline & $\begin{array}{c}\text { Typ e } 2 \text { DM } \\
(n=78)\end{array}$ & $\begin{array}{c}\text { No } \\
(n=528)\end{array}$ & & $\begin{array}{c}\text { Type 2 DM } \\
(\mathrm{n}=69)\end{array}$ & $\begin{array}{c}\text { No } \\
(n=480)\end{array}$ & \\
\hline$\overline{\text { Age }}$ & $51.1 \pm 7.6$ & $48.8 \pm 9.4$ & 0.016 & $50.8 \pm 7.7$ & $48.5 \pm 9.4$ & 0.021 \\
\hline Waist circumference & $94.4 \pm 9.5$ & $91.1 \pm 9.4$ & 0.503 & $95.5 \pm 8.7$ & $91.7 \pm 9.3$ & 0.924 \\
\hline BMI & $29.7 \pm 4.2$ & $29.2 \pm 4.4$ & 0.312 & $30.2 \pm 4.0$ & $29.6 \pm 4.4$ & 0.191 \\
\hline Triglycerides & $195.3 \pm 138.8$ & $155.4 \pm 88.6$ & 0.008 & $196.4 \pm 145.4$ & $155.9 \pm 88.0$ & 0.003 \\
\hline HD L cholesterol & $57.2 \pm 108.3$ & $47.9 \pm 11.1$ & 0.001 & $59.6 \pm 115.0$ & $48.0 \pm 11.1$ & 0.001 \\
\hline LDL chdesterol & $156.2 \pm 101.8$ & $141.5 \pm 31.8$ & 0.007 & $159.2 \pm 107.1$ & $142.5 \pm 32.3$ & 0.011 \\
\hline Cholester ol total & $232.8 \pm 94.8$ & $216.3 \pm 37.9$ & 0.001 & $2356 \pm 99.5$ & $217.4 \pm 38.5$ & 0.006 \\
\hline Fasting blood glucose & $124.4 \pm 105.4$ & $90.4 \pm 10.7$ & 0.001 & $126.87 \pm 111.7$ & $90.1 \pm 10.8$ & 0.001 \\
\hline 2-hPP bl ood glucose & $226.5 \pm 31.6$ & $116.9 \pm 27.5$ & 0.001 & $226.7 \pm 115.2$ & $135.8 \pm 28.0$ & 0.001 \\
\hline Systolic BP & $147.6 \pm 25.4$ & $142.2 \pm 27.3$ & 0.169 & $142.7 \pm 20.5$ & $140.9 \pm 27.4$ & 0.010 \\
\hline Diastolic BP & $90.8 \pm 11.4$ & $89.1 \pm 14.4$ & 0.047 & $90.1 \pm 11.4$ & $88.6 \pm 14.2$ & 0.071 \\
\hline
\end{tabular}

As may be seen in Table 3, after multivariate analysis, respondents with MetS according to NCEP-ATP III criteria had a 4.7 times greater risk for experiencing type $2 \mathrm{DM}$ when under observation in the second year (CI 95\%: 3.4-6.5), while respondents with MetS based on IDF criteria had a 4.1 times greater risk (CI 95\%: 3.0-5.7). The risk of type $2 \mathrm{DM}$ increased with increasing age. The age group of $35-43$ years had a 2.6 times greater risk (CI 95\% 1.2-5.6), while the age group of $\geq 44$ years had a 4.3 times risk (CI 95\%: 2.1-8.9). The SM component having the greatest influence on the occurrence of type $2 \mathrm{DM}$ was the blood glucose level of $\geq 100 \mathrm{mg} / \mathrm{dL}$. Respondents with fasting glucose level of $\geq 100 \mathrm{mg} / \mathrm{dL}$ had a 4.6 times greater risk of DM (CI 95\%:3.0-7.1). Other
MetS components that carried a risk of type 2 DM were central obesity, blood pressure of $>130 /$ $85 \mathrm{mmHg}$, hypertriglyceridemia, and low HDL cholesterol level.

\section{DISCUSSION}

The results of the analysis showed that the prevalence of MetS in non-DM subjects based on IDF criteria was $1.5 \%$ lower compared with NCEP-ATP III criteria. These results agree with previously conducted studies in several Asian countries. The Hong Kong Cardiovascular Risk Factor Prevalence Study (CRISPS) in China showed that the MetS prevalence in 1679 subjects according to NCEP-ATP III criteria (14.5\%) was also higher than that based on IDF $(11.4 \%){ }^{(20)} \mathrm{A}$

Table 3. Risk factors for type 2 DM after 2 years

\begin{tabular}{|c|c|c|c|c|}
\hline \multirow{2}{*}{ Variable } & \multicolumn{2}{|c|}{ Diabetes mellitus (\%) } & \multirow{2}{*}{ OR (CI 95\%) } & \multirow{2}{*}{$\mathbf{p}$} \\
\hline & No & Yes & & \\
\hline IDF MetS Criteria & 87.4 & 12.6 & $4.1(3.0-5.7)$ & 0.001 \\
\hline ATP III MetS Criteria & 87.0 & 13.0 & $4.7(3.465)$ & 0.001 \\
\hline \multicolumn{5}{|l|}{ Age group } \\
\hline $25-35$ years & 98.8 & 1.2 & - & \\
\hline 3543 years & 96.4 & 3.6 & $2.6(1.2-5.6)$ & 0.013 \\
\hline $44-51$ years & 93.2 & 6.8 & $4.3(2.1-8.8)$ & 0.001 \\
\hline $52-65$ years & 92.3 & 7.7 & $4.3(2.1-89)$ & 0.001 \\
\hline Central obesity & 91.9 & 8.1 & $2.5(1.7-35)$ & 0.001 \\
\hline Blood pressure $>130 / 85 \mathrm{mmHg}$ & 89.0 & 11.0 & $1.8(1.2-2.6)$ & 0.003 \\
\hline Fasting bl ood glucose $>100 \mathrm{~m}$ g/dL & 80.5 & 19.5 & $4.6(3.0-7.1)$ & 0.001 \\
\hline Hypertriglyceridemia & 93.2 & 6.8 & $1.8(1.2-26)$ & 0.004 \\
\hline Low HDL cholester ol & 93.4 & 6.6 & $1.7(1.2-2.4)$ & 0.002 \\
\hline
\end{tabular}


population study in Bangladesh showed that MetS based on NCEP-ATP III criteria was higher (30.7\%) compared with IDF (24.5\%). ${ }^{(21)}$ Similarly a study in Kuala Lumpur, Malaysia, showed that MetS based on NCEP-ATP III was higher (41.4\%) than that based on IDF (38.2\%). ${ }^{(22)}$

However, our results are different from those of Adam et al..$^{(3)}$ who reported that IDF-based MetS prevalence in the European population of Adelaide, Australia, was higher (22.8\%) compared with the MetS prevalence based on NCEP-ATP III (15\%). Similar results were also shown by Nilson ${ }^{(23)}$ who reported that IDF-based MetS prevalence of $37.2 \%$ was higher than the MetS prevalence of $24.7 \%$ based on NCEP-ATP III criteria. These differences in the results were due to the fact that IDF criteria require the presence of central obesity for determination of MetS occurrence. Even though the values of the other components exceed the normal values, in the absence of central obesity, the subjects will not be categorized as having MetS. In addition, there is the difference in the ethnicity of the populations between Asia and Australia/Europe, for which the cut-off points of waist circumference are different. ${ }^{(4)}$

The MetS prevalence in females was higher than in males, both according to NCEP-ATP III and IDF criteria. These results are in line with the results of a study in Bali, ${ }^{(24)}$ where the MetS prevalence was $18.2 \%$ (16.6\% for males and $20.0 \%$ for females). Similarly, in an American study, a higher MetS prevalence was obtained for females $(24 \%)$, whereas for males it was $23.4 \% .{ }^{(25)}$ Females are more at risk for experiencing MetS, because physically they have a greater chance for increasing their body mass index. The premenstrual syndrome and the postmenopausal period give rise to an easier accumulation of body fat as a result of hormonal processes, which interfere with the action of insulin. ${ }^{(25)}$ Furthermore, the MetS prevalence obtained also depends on the population under study. In the present study, there was a higher proportion of females among the participating subjects.
Respondents with MetS have greater waist circumference, BMI, LDL, total cholesterol, and mean systolic and diastolic pressures, in comparison with those without MetS, according to NCEP-ATP III criteria as well as IDF criteria. The mechanism causing the occurrence of the metabolic syndrome is based on insulin resistance and central obesity (visceral fat). Visceral fat is metabolically more active than peripheral fat. The accumulation of adipocytes will increase the free fatty acids resulting from lipolysis, which will reduce the sensitivity to insulin. This insulin resistance and hyperinsulinemia in turn will cause metabolic changes, leading to hypertension, dyslipidemia, increased inflammatory responses and coagulation, by means of complex mechanisms such as endothelial dysfunction and oxidative stress. ${ }^{(26,27)}$

The proportion of MetS, both that based on NCEP-ATP III criteria and on IDF criteria increases with advancing age. The number of components associated with MetS also increases, and at a more advanced age the components are greater in number. The occurrence of MetS at a younger age requires close attention. Uncontrolled MetS occurring in younger persons will at a future date carry the risk of atherosclerosis that is associated with MetS, resulting in the occurrence of cardiovascular disease and DM. ${ }^{(26)}$

The MetS criteria, whether based on NCEPATP III or IDF, were excellent for determining the occurrence of MetS in our present study. Similar study results were found by Moy and Bulgiba, ${ }^{(22)}$ who stated that although there was excellent agreement between NCEP-ATP III and IDF, 7.6\% of the respondents were not diagnosed as having MetS when using the IDF criteria. The study of Chackrewarthy et al. ${ }^{(28)}$ in Ceylon also showed that the IDF criteria failed to identify $21 \%$ of males and $7 \%$ of females who had been declared as having MetS based on the NCEPATP III criteria. This was because respondents who had no central obesity, but had high cardiometabolic risk factors such as blood pressure of $\geq 130 / 85 \mathrm{mmHg}$, fasting blood glucose of $\geq 100$ $\mathrm{mg} / \mathrm{dL}$, and low HDL cholesterol levels, were 
not diagnosed with MetS according to the IDF criteria requiring the presence of central obesity plus two other MetS components. ${ }^{(22,28)}$

On follow up observations, type $2 \mathrm{DM}$ was found in $78(13.0 \%)$ of the respondents with NCEP-ATP III based MetS and in 69 (12.6\%) of the respondents with IDF-based MetS. These respondents with DM had a greater mean number of MetS components than the non-DM respondents. The risk of type $2 \mathrm{DM}$ in respondents with MetS according to NCEP-ATP III criteria was 4.7 times greater, whereas respondents with MetS according to IDF was 4.1 greater. These results show that MetS is closely associated with type 2 DM. Similar studies in China showed that MetS according to both NCEP-ATP III and IDF can predict the DM incidence, with risks of 4.1 (95\% CI 2.8-6.0) and $3.5(2.3-5.2)$, respectively. ${ }^{(20)}$ This is in line with the results of a review of 13 cohort studies that was conducted by Ford, Li and Sattar, ${ }^{(13)}$ also showing that subjects with MetS by NCEP ATP III criteria have a 3.53 times higher risk, and by IDF criteria a 4.42 times higher risk for the occurrence of DM. Cohort studies conducted by Wilson et al. ${ }^{(29)}$ also showed that the risk of DM was 6.9 times higher in subjects with MetS within an 8 -year period. The more MetS components, the higher the risk.

The factors affecting the occurrence of type $2 \mathrm{DM}$, in addition to age, include MetS components such as central obesity, fasting glucose level of $\geq 100 \mathrm{mg} / \mathrm{dL}$, blood pressure of $>130 / 85 \mathrm{mmHg}$, hypertriglyceridemia and low HDL cholesterol level. Fasting glucose level of $\geq 100 \mathrm{mg} / \mathrm{dL}$ is the component with the greatest risk (4.6 times greater) for occurrence of type 2 $\mathrm{DM}$ after 2 years. The aging process causes a reduction in the capacity of pancreatic $\beta$ cells to produce insulin. In individuals with MetS, insulin resistance is increasingly more severe and finally the insulin secretion decreases, so that there is hyperglycemia and manifestations of type 2 DM. ${ }^{(26,27)}$

The results of the above analysis show that MetS prevalence is relatively high in the five kelurahan in Bogor. The metabolic syndrome can be used as predictor of type 2 DM. Screening programs and routine monitoring of MetS components are necessary for detecting the onset of type $2 \mathrm{DM}$, in addition to being supported with changes in life style, dietary pattern, and increased physical activity. The analysis has several limitations, because it did not differentiate between genders, although it is known that there is a difference in waist circumference between females and males. This was because there were more females than males among the subjects.

\section{CONCLUSIONS}

Both NCEP-ATP III and IDF criteria can be used as predictors of type $2 \mathrm{DM}$ in subjects with MetS. However, the NCEP-ATP III criteria are more properly used for determining MetS as compared with the IDF criteria. Screening programs and routine monitoring of MetS components are necessary for detecting the onset of type 2 DM.

\section{CONFLICT OF INTERESTS}

The authors declare that they have no conflict of interests.

\section{ACKNOWLEDGMENTS}

We wish to express our gratitude to the Head of the Bogor City Health Service and staff, all respondents of the Cohort Study of NCD Risk Factors and all parties who helped in the conduct of this study. This study was financed by funds from the DIPA (Daftar Isian Penggunaan Anggaran) Badan Litbangkes for 2011-2012.

\section{REFERENCES}

1. Huang P. A comprehensive definition for metabolic syndrome. Dis Models Mech 2009; 2:231-7.

2. Deepa M, Farooq S, Datta M, et al. Prevalence of metabolic syndrome using WHO, ATP III and 
IDF definition in Asian Indians: the Chennai urban rural epidemiology study (CURES-34). Diabetes Metab Res Rev 2007;23:127-34.

3. Adams RJ, Appleton S, Wilson DH, et al. Population comparison of two clinical approaches to the metabolic syndrome. Diabetes Care 2005;28:2777-9.

4. Grundy MS, Cleemen JI, Daniels SR, et al. Diagnosis and management of the metabolic syndrome: an American Heart Association/ National Heart, Lung and Blood Institute Scientific Statement. Circulation 2005;112: 2375-2.

5. Soewondo P, Purnamasari D, Oemardi M, et al. Prevalence of metabolic syndrome using NCEP/ ATP III criteria in Jakarta, Indonesia: The Jakarta Primary Non-communicable Disease Risk Factors Surveillance 2006. Acta Med IndonesIndones J Intern Med 2010,42:199-203.

6. Pusparini. Central obesity, metabolic syndrome dan diabetes melitus tipe dua. Univ Med 2007; 26:195-204.

7. Hanley AJG, Karter AJ, Willimas K, et al. Prediction of type 2 diabetes mellitus with alternative definitions of the metabolic syndrome: The Insulin Resistance Atherosclerosis Study. Circulation 2005;112: 3713-21.

8. Povel CM, Beulens JW, Van der Schouw YT, et al. Metabolic syndrome model definitions predicting type 2 diabetes and cardiovascular disease. Diabetes Care 2013;36:362-8.

9. Shin J A, Lee Jin-Hee, Lim Sun-Young, et al. Metabolic syndrome as a predictor of type 2 diabetes, and its clinical interpretations and usefulness. J Diabetes Invest 2013;4:334-43.

10. Sattar N, McConnachie A, Shaper AG, et al. Can metabolic syndrome usefully predict cardiovascular disease and diabetes? Outcome data from two prospective studies. The Lancet 2008;371:1927-35.

11. Dekker JM, Girman C, Rhodes T, et al. Metabolic syndrome and 10-year cardiovascular disease risk in the Hoorn Study. Circulation 2005;112: 666-73.

12. Flato MO, Parush N, El-Hay T, et al. Predictive models for type 2 diabetes onset in middle-aged subjects with the metabolic syndrome. Diabetol Metab Syndr 2013;5:1-9.

13. Ford ES, Li C, Sattar N. Metabolic syndrome and incident diabetes. Diabetes Care 2008;31: 1898-904.

14. Julianty P, Riyadina W, Sirait A, dkk. Laporan Studi Kohor Faktor Risiko Penyakit Tidak
Menular 2014. Badan Penelitian dan Pengembangan Kesehatan;2015.

15. Third Report of the National Cholesterol Education Program (NCEP) Expert Panel on Detection, Evaluation, and Treatment of High Blood Cholesterol in Adults (Adult Treatment panel III). National Heart, Lung, and Blood Institute. National Institutes of Health. NIH Publication 20002.No.02-5215.

16. International Diabetes Federation. The IDF consensus worldwide definition of the Metabolic Syndrome. International Diabetes Federation; 2006.

17. American Diabetes Association. Diagnosis and classifcation of diabetes mellitus. Diabetes Care 2012;35:S69-S71.

18. Riyadina W, Musadad A, Rahajeng E, et al. Buku Pedoman Pemeriksaan Studi Kohor Risk factorsPTM. Badan Penelitian dan Pengembangan Kesehatan;2014.

19. Streiner DC, Norman GR. Health measurement seals. $2^{\text {nd }}$ Ed. New York: Oxford University Press; 2000.

20. Cheung B, Nelson MS, Man YB, et al. Development of diabetes in Chinese with the metabolic syndrome. Diabetes Care 2007;30: 1430-6.

21. Bhowmik B, Afsana F, Siddiquee T, et al. Comparison of the prevalence of metabolic syndrome and its association with diabetes and cardiovascular disease in the rural population of Bangladesh using the modified National Cholesterol Education Program Expert Panel Adult Treatment Panel III and International Diabetes Federation definitions. J Diabetes Invest 2015;6:280-8.

22. Moy F, Buigiba A. The modified NCEP ATP III criteria maybe better than the IDF criteria in diagnosing metabolic syndrome among Malays in Kuala Lumpur. BMC Public Health 2010;10:678. DOI: 10.1186/1471-2458-10-678.

23. Saukkonen T, Jokelainen J, Timonen M, et al. Prevalence of metabolic syndrome components among the elderly using three different definitions: a cohort study in Finland. Scand J Prim Health Care 2012;30:29-34.

24. Dwipayana MP, Suastika K, Saraswati IMR, et al. Prevalensi Sindroma Metabolik pada Populasi Penduduk Bali, Indonesia. J Peny Dalam 2011; 12:1-5.

25. Juutilainen A, Kortelainen S, Lehto S, et al. Gender difference in the impact of type 2 diabetes on coronary heart disease risk. Diabetes Care 2004;27:2898-904. 
26. Rohman. Patogenesis dan terapi metabolic syndrome. J Kardiol Ind 2007;28:160-8.

27. Ceriello A, Motz E. Is oxidative stress the pathogenic mechanism underlying insulin resistance, diabetes and CVD? Arterioscler Thromb Vac Bio 2004;24:816-23.

28. Chackrewarthy S, Gunasekera D, Pathmeswaren A, et al. A comparison between revised NCEP
ATP III and IDF definitions in diagnosing metabolic syndrome in an Urban Sri Lankan population: the Ragama Health Study. ISRN Endocrinol 2013; Article ID 320176,7 pages.

29. Wilson P, D'Agostino R, Parise H, et al. Metabolic syndrome as a precursor of cardiovascular disease and type 2 diabetes mellitus. Circulation 2005;112:3066-72. 